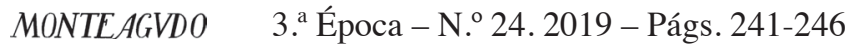

\title{
La pretenciosa educación en el Colegio Militar Leoncio Prado de La Ciudad y los perros (1963)
}

\author{
Jesús Miguel Delgado del Águila \\ Universidad Nacional Mayor de San Marcos
}

RESUMEN:

En la novela La ciudad y los perros (1963), del escritor peruano Mario Vargas Llosa, se muestra el desbalance que se genera en los cadetes del Colegio Militar Leoncio Prado que se dedican a estudiar enfáticamente (como ocurre con el caso del Esclavo): conduce a la envidia de quienes dominan poco alguna materia, además de que los maestros no apoyan su educación. Un acontecimiento similar es cuando se origina lo opuesto: no se proyecta un buen porvenir en quien no estudia (caso del Jaguar). Sin embargo, pasa algo particular con este protagonista: no necesitó ir a una cárcel luego de haber asesinado al Esclavo para reflexionar sobre su vida, bastó con que se le brindara la oportunidad de aprovechar su existencia en hacer buenas obras para su reivindicación. Esa posibilidad lo configura como un personaje más civilizado y ético.

\section{PALABRAS CLAVE:}

Educación, violencia, análisis literario, personaje, clasificación.

\begin{abstract}
:
In the novel The Time of the Hero (1963), Peruvian writer Mario Vargas Llosa, shows the imbalance that is generated in the cadets of the Leoncio Prado Military Academy that are dedicated to study emphatically (as in the case of the Slave): it leads to the envy of those who dominate a few subjects, in addition to the fact that the teachers do not support their education. A similar event is when the opposite happens: no hope is seen in those who do not study (case of the Jaguar). However, something special happens with this protagonist: he did not need to go to a prison after having killed the Slave to reflect on his life, it was enough to be given the opportunity to take advantage of his existence in doing good works for his vindication. That possibility it configures him as a more civilized and ethical character.
\end{abstract}

\section{KEYWORDS :}

Education, violence, literary analysis, character, classification. 


\section{Introducción}

El adiestramiento recibido del Colegio Militar Leoncio Prado, con respecto a los educadores que imparten conocimientos a los cadetes, se configura en función de un tratamiento violento principalmente. Sin embargo, no es suficiente esa modalidad particular para asegurar que el alumno rinda académicamente, ya que los contenidos éticos y sociales se desplazan para asociarse únicamente con la creación de su propia experiencia; es decir, la educación recibida no construirá adecuadamente la expectativa de conducta que se tiene de los leonciopradinos.

Para ello, se hará una subdivisión de este estudio en cuanto los niveles de aprendizaje por los cuales atraviesa el cadete, como también, los cargos que se les asigna; todo ello con la intención de confirmar la existencia de una autorregulación de los personajes como una actitud frente a la sociedad para desenvolverse libremente (éticamente o viceversa), siendo la formación militar una alternativa o un complemento de las vivencias, mas no de una educación estricta.

\section{Triángulo jerárquico de los niveles de aprendizaje}

En esta oportunidad, cuestiono la intensidad de violencia inherente al sujeto que desintegra la optimización en los rendimientos académicos; es decir, resulta recíproco el énfasis ético con el educativo, de tal modo que los efectos obtenidos consiguen una satisfacción personal o una contraparte. A partir de la novela La ciudad y los perros (1963), se construye una jerarquía convencional en torno a la forma con la que predomina el tratamiento de la educación y la postura ética.

Como primer factor, se hallan todos aquellos individuos que obtienen buenos resultados sin necesidad de obrar mal. En otras palabras, son alumnos eficientes y modelos humanos a la vez. Ellos se preparan bien para los exámenes, rinden con éxito los cursos asignados y están conformes con la enseñanza que reciben en función de los rubros establecidos. En esta clasificación, se encuentra el Esclavo. Ricardo Arana no necesita negociar el examen resuelto de Química con el Círculo. Más bien, él se dispone a ayudar, en una ocasión, a su compañero Alberto para que realice óptimamente su prueba.

La segunda manera de incluirse en la educación y la ética es mediante una postura mediocre o intermedia. Aquí, se ubican los personajes que rara vez estudian o lo hacen erróneamente cuando predomina una urgencia. Verbigracia, una evaluación próxima. En relación con la conducta ética que ellos manifiestan, esta se deja evaluar por sus comportamientos violentos, mas estos no son de gran gravedad, aunque sí se evidencian. Ejemplos de personajes de este tipo los conforma la mayoría de alum- 
nos, pero especialmente lo consigue el Poeta, quien recepciona saberes y actúa de modo convencional tan solo para poder sobrevivir en ese medio caótico.

La tercera forma se localiza en los estudiantes que sacan malas calificaciones. Rosario Ortega Ruiz (1998: 45) señalaba que un joven que abusa de los demás, rara vez, es un alumno académicamente brillante. Más bien, suele estar en grupos que no obtienen resultados óptimos, sin importarle tampoco. Esto es posible, porque al referirse uno a la exclusión intelectual, se muestra como producto la inclusión de la violencia en los humanos. El caso más notorio del texto es el Jaguar: él recurre al robo y otros actos no permitidos para aprobar los exámenes. Sus calificaciones son deficientes de por sí y su mediocridad profesional es la que se puede destacar en su destino.

Con respecto a estas tres maneras de apreciar el nivel de aprendizaje, se retoma una clasificación ascendente, pero entonces ¿qué ocurre con el Jaguar cuando imparte conocimientos académicos a Teresa?, ¿se cuenta con la expectativa de que la maldad conduzca al bien? Estas pautas modifican totalmente la segmentación que se acaba de hacer. Por ende, se explica luego del gráfico qué es lo que produce la desestructuración del triángulo jerárquico de los niveles de aprendizaje.

\section{NIVELES DE APRENDIZAJE}

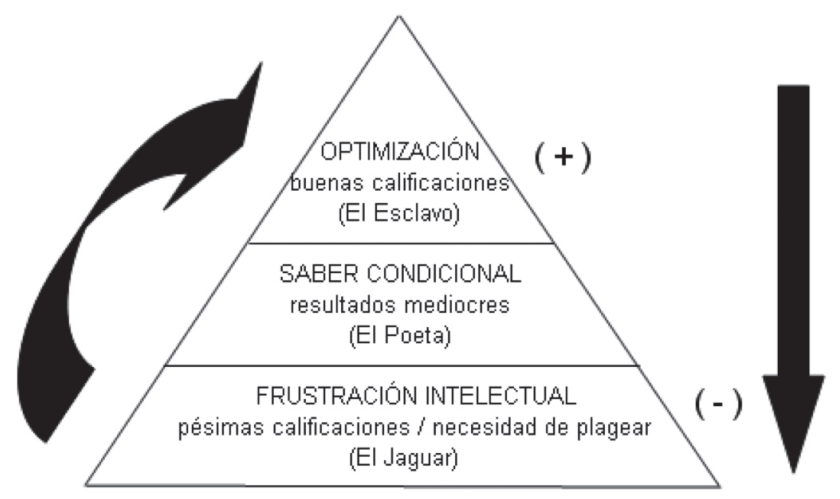

Asumiendo que un personaje, influenciado por sus actos bélicos y antiéticos, no efectúa actos de bondad o modificaciones conscientes de su conducta, con La ciudad y los perros (1963), acontece lo inesperado. Vargas Llosa plantea un modelo humano que se caracterizará por su reivindicación personal en la sociedad. El Jaguar no necesitó ir a una cárcel de verdad, luego de la muerte del Esclavo, para reflexionar sobre su vida, ya que bastó que se le brindara la oportunidad de aprovechar su existencia en hacer acciones buenas (recomendación del teniente Gamboa al cadete cuando se 
está retirando del Colegio Militar). En fin, el cambio es notorio en el Jaguar, debido a que pasa de ser un frustrado intelectual a un individuo trabajador, responsable y empedernido por la superación. Esta actitud no solo la logra cuando sale del Colegio Leoncio Prado, sino que anteriormente ya mostraba indicios al educar a Teresa. Asimismo, se apropia de ese comportamiento para ser aceptado por esa chica que le gusta. Las modificaciones constantes y convencionales permiten desestructurar este nuevo triángulo jerárquico. En consecuencia, se consolida el rechazo a la catalogación individual de los personajes (se distingue del Poeta y el Esclavo).

\section{Triángulo jerárquico de los cargos asignados por los alumnos}

En el Colegio Militar Leoncio Prado, existen cargos que caracterizan a los cadetes como entidades responsables del orden interno, pero también prevalecen desorganizaciones que crean convenios para la realización de trabajos autónomos y mal fundados, como los del Círculo. Nuevamente, predomina una clasificación tripartita que obedece a una jerarquía de dominación.

En primer lugar, se encuentran los brigadieres de secciones. Estos son conformados por cadetes que tienen altas calificaciones y poseen disponibilidad para responsabilizarse de sus demás compañeros. Al respecto, Aristóteles (1990: 253) argumenta que la superioridad que han alcanzado revela su virtud, característica principal de estos muchachos. En distintas ocasiones, quienes cumplen este rol ayudan a los militares a informarles del orden y el desorden generados por los alumnos. Muchas veces, también, colaboran en el trato amical que exige la convivencia de tantos estudiantes. En una oportunidad, el brigadier Arróspide representa a toda la sección para denunciar al Jaguar de soplón, ya que su función consiste en proteger y resguardar a sus compañeros. Los brigadieres disputan bajo la concepción de la justicia, con la finalidad de disolver todo temor engendrado por los abusadores.

En una segunda etapa, se hallan los imaginarias. La responsabilidad que les demanda a ellos no es por mérito, como sí se origina con los brigadieres, sino que su elección es por azar o decisión de las autoridades militares. Al no ser el rol que cumplen de su agrado servirá para que tiendan a incumplir las normas que se les asigna o, en todo caso, desarrollarán un trabajo deficiente. En una ocasión, el Jaguar no quiere desempeñarse en ese cargo asignado y será el Esclavo quien lo remplace por amenaza.

El tercer rango lo ocupan los del Círculo, quienes tienen al mando al Jaguar para ocuparse de actos informales y violentos. Roban exámenes, prendas de vestir, hacen bromas pesadas, se pelean con los otros cadetes y están comunicados de todo. $\mathrm{Su}$ creación se justifica por el hecho de que no les gusta cómo está siendo llevada a cabo 
la organización de los alumnos de quinto año, quienes solo pretenden abusar de los alumnos de grados inferiores. Ellos, en cambio, tratarán de dominar, conservar o modificar los instrumentos del poder permanentemente. Para esto, utilizarán la violencia colectiva como su propia arma de lucha. En torno a ello, Landowski (2007: 20) señalaba que un grupo dominante, como buen asimilador, no rechaza a nadie. Por el contrario, se siente generoso, acogedor y abierto al exterior. El Rulos, el Boa y el serrano Cava no son los únicos del tercer año que asimilan la violencia para no dejarse golpear por los alumnos de quinto año, sino que toda la sección se vuelve partícipe y colaboradora de esa violencia colectiva. Al mismo tiempo, cualquier diferencia de comportamiento algo marcada, que se desligue de las normas y las bases establecidas, significará una extravagancia carente de sentido. Ello justifica que el Jaguar se sienta indignado y con ansias de venganza cuando el serrano Cava (miembro del Círculo) es expulsado del colegio.

La jerarquía mencionada se desestructura al percibirse que es esa pequeña banda delincuencial la dominante en los roles que cumplen los otros cadetes. Por lo tanto, existe una rebeldía inmoral por parte de los integrantes del Círculo. Esta anomalía se explicará luego de la inserción del triángulo jerárquico.

\section{Cargos asignados por los alumnos}

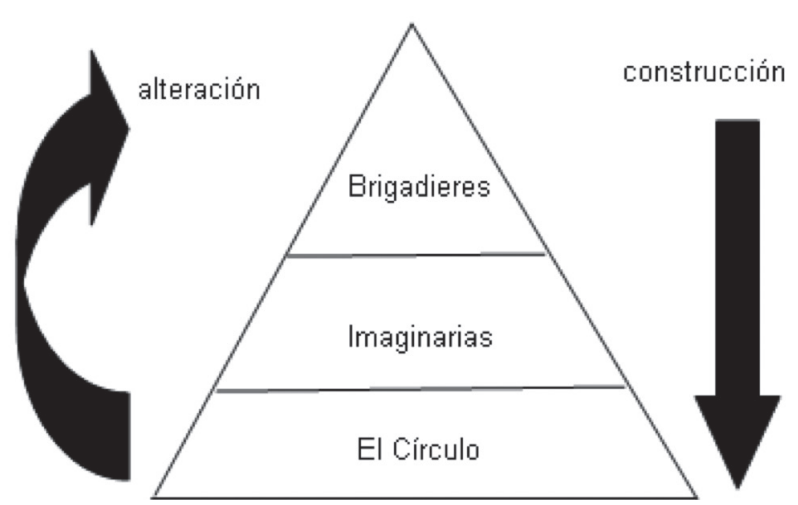

Según Lubomír Doležel (1999: 161), el agente subordinado está a disposición de quien ostenta el poder, pero eso también conlleva una contraparte: al desarrollarse todo mediante estructuras rigurosas de poder, como las militares, los subordinados se despersonalizan (no ocurre lo mismo cuando se trata de estructuras menos rígidas). Por lo tanto, quienes dependen amargamente de una autoridad están en la constante búsqueda de una rebelión potencial hacia quien manifieste el poder. El Jaguar es el principal rebelde del orden. Esto trae como consecuencia que los demás cadetes in- 
tenten imitarlo. Se cumple en este protagonista lo que designa Hannah Arendt (2008: 57) como la extrema forma de violencia, la cual consiste en la dinámica de «Uno contra Todos» (cuando el Jaguar arrebata el poder a los imaginarias y los brigadieres, como también a diversos cadetes y autoridades); en oposición a la extrema forma de poder, que es «Todos contra Uno» (que se origina cuando el Jaguar es separado de la figura de poder y terror que lo caracteriza, al acusársele de soplón por casi toda la sección). Igualmente, los brigadieres llegan a alterar su modo de ser, en el caso de Arróspide, debido a que permite que los alumnos tiren contra, roben o consuman alcohol y cigarrillos. El silencio sobre la maldad que visibilizan estos encargados los convierte en cómplices.

\section{A modo de conclusión}

La disciplina, los cargos asignados (como los brigadieres y los imaginarias) y cualquier otra implicancia de intervención militar sobre el cadete del Colegio Militar Leoncio Prado no asegurará su desenvolvimiento, tal como se demostró con el personaje el Jaguar, quien desintegró una organización interna de la institución, al igual que adaptar las normas a su propio criterio. En consecuencia, al mencionar una conducta disciplinada de los sujetos, se hace referencia a una simulación o una virtualización de una realidad concreta, siendo esta no una definitiva, aplicada o compatible con la sociedad no institucional (familiar, amical, laboral, etc.).

\section{Referencias bibliográficas}

Arendt, Hannah, Sobre la violencia, Madrid, Alianza Editorial, 2008.

Aristóteles, Retórica, trad. de Quintín Racionero, Madrid, Gredos, 1990.

Delgado Del Águila, Jesús Miguel, Protagonismo violento y modos de representación en La ciudad y los perros (1963), tesis de licenciatura, Lima, Universidad Nacional Mayor de San Marcos, 2017.

Doležel, Lubomír, Heterocósmica. Ficción y mundos posibles, trad. de Félix Rodríguez, Madrid, Arco/Libros, 1999.

Landowski, Eric, Presencias del otro, trad. de Desiderio Blanco, Lima, Fondo Editorial de la Universidad de Lima, 2007.

Ortega Ruiz, Rosario, et al., La convivencia escolar: qué es y cómo abordarla, Andalucía, Programa Educativo de Prevención de Maltrato entre compañeros y compañeras, 1998.

Vargas Llosa, Mario, La ciudad y los perros, ed. conmemorativa del cincuentenario, Madrid, Alfaguara, Real Academia Española, 2012. 